Article

\title{
The Drivers of Policies to Limit the Spread of COVID-19 in Europe
}

\author{
Sebastien Bourdin ${ }^{1, *(\mathbb{D})}$, Slimane Ben Miled ${ }^{2}$ and Jamil Salhi ${ }^{2,3}$ \\ 1 Métis Lab, EM Normandie Business School, 76600 Le Havre, France \\ 2 Institut Pasteur de Tunis, University of Tunis el Manar, Tunis 1068, Tunisia; \\ slimane.benmiled@gmail.com (S.B.M.); jamil.salhi@enit.rnu.tn (J.S.) \\ 3 School of Business, Esprit School of Business, Tunis 2083, Tunisia \\ * Correspondence: sbourdin@em-normandie.fr
}

Citation: Bourdin, Sebastien, Slimane Ben Miled, and Jamil Salhi. 2022. The Drivers of Policies to Limit the Spread of COVID-19 in Europe. Journal of Risk and Financial Management 15: 67. https:// doi.org/10.3390/jrfm15020067

Academic Editors: Matheus R. Grasselli and Thanasis Stengos

Received: 29 November 2021

Accepted: 28 January 2022

Published: 1 February 2022

Publisher's Note: MDPI stays neutral with regard to jurisdictional claims in published maps and institutional affiliations.

Copyright: (C) 2022 by the authors. Licensee MDPI, Basel, Switzerland. This article is an open access article distributed under the terms and conditions of the Creative Commons Attribution (CC BY) license (https:/ / creativecommons.org/licenses/by/ $4.0 /)$.
Abstract: While many articles have analyzed the effectiveness of the policies that aimed to limit the spread of COVID-19, very little research work has examined the determinants that drove these policies. Therefore, we proposed to study the determinants that led government authorities to implement more or less restrictive policies to limit the spread of the pandemic. Using the COVID-19 stringency index, we highlighted a positive effect of the incidence rate on the stringency level. Patient capacity in intensive care units was also a key variable. This is indicative of the capacity of countries to have a sufficient and appropriate health system to absorb such pandemic crises. On the other hand, we show that epidemiological data regarding the risk of excess mortality (diabetes, cancer, and cardiovascular pathologies) had a negative effect. We conclude by recalling the importance of policy coordination between countries when it comes to lowering the stringency levels of measures, in order to avoid a resurgence of the epidemic.

Keywords: stringency; lockdown; COVID-19; public policies

\section{Introduction}

The unprecedented crisis we are currently experiencing with the coronavirus pandemic, as with any global epidemic, is part of an evolving spatiotemporal process: The hierarchy of the territories affected by high mortality linked to COVID-19 evolves over time; this is what we call 'the kinetics of the pandemic' in medical terms. After its outbreak in Wuhan's megalopolis, the virus initially spread from one neighborhood to another in nearby Asian metropolises and could not remain Asian; since Asia, and China in particular, has many relations with other continents. From this perspective, the epidemic took advantage of globalization forces to spread to the most economically integrated metropolitan areas (Bourdin et al. 2021).

In an attempt to slow the pandemic and flatten the curve, governments have implemented many non-medical responses at the national and local scale (Bourdin et al. 2021). Thus, in order to limit the damage caused by the pandemic, states have taken more or less drastic measures, more or less staggered over time, according to different parameters. These included travel restrictions, bans on public gatherings, school closures, interruption of non-essential services, and widespread containment (IMF 2020). The underlying objective was to protect the populations' health and avoid overloading hospital beds, especially intensive care units. As Bal et al. (2020) point out, coronavirus puts considerable stress on healthcare systems.

Given the unpreparedness of many states for such shocks to the healthcare system (Forman et al. 2020), it is not surprising to observe geographical variations in the implementation of these restrictive measures. Indeed, the way unexpected events are managed is far from uniform across the world (Weick and Sutcliffe 2011). 
Faced with the different pandemic waves, and while waiting for vaccination campaigns to provide sufficient herd immunity to go back to normal, most European leaders implemented restrictions in an attempt to stop the spread of the virus. Population containment has been the most commonly adopted solution, and more than half of the world's population has been in this situation. However, in Europe, some countries, such as Sweden, opted for herd immunity instead. On this subject, Kamerlin and Kasson (2020) studied Sweden's policy and showed that this country had very similar results to the belatedly introduced containment strategies. On the other hand, it resulted in more deaths than in countries that implemented containment policies earlier. They also added that the Swedish strategy increased the demand for health care.

Several studies have analyzed the effectiveness of lockdown measures in combating the spread of coronavirus. Using a sample of 202 states, Alfano and Ercolano (2020) showed that lockdowns reduced the number of new cases in the countries that implemented this measure, compared with the countries that did not. In the context of an analysis of 11 European countries, Flaxman et al. (2020) showed that widespread containment measures significantly reduced transmission of the virus. Figueiredo et al. (2020) came to the same conclusion based on the Chinese example. They showed a decrease in the number of deaths 10 days after the implementation of containment. Another study on Chinese provinces concluded that containment measures successfully slowed the increase in confirmed cases (Maier and Brockmann 2020). The authors also showed that mitigation strategies for the most vulnerable populations were effective. Lau et al. (2020) obtained similar results based on the example of Wuhan. In a regional analysis at Indian state scale, Sardar et al. (2020) concluded that such restrictive measures significantly affected reproduction numbers (R0).

Other, more refined, analyses are not limited to assessing the effect of containment on mortality. They assessed the effect of the measures' stringency on controlling the spread of the virus. In the case of the United Kingdom, Davies et al. (2020) used a stochastic transmission model to explore the effects of four types of intervention (school closures, physical remoteness, protection of people aged 70 or over, and self-isolation of symptomatic cases) on the number of COVID-19 patients. They point to the positive effect of such measures. Other researchers have also analyzed the effects of non-pharmaceutical interventions (quarantine and isolation, border restrictions, and physical distancing of the population) in different territorial contexts, such as in Hong Kong (Cowling et al. 2020), Brazil (Jorge et al. 2020), Latin America (Zhu et al. 2020), and Italy (Caselli et al. 2020; Bourdin et al. 2021). They showed a reduction in the transmission of COVID-19 associated with these measures.

Overall, while there is now a growth in publications that assess the effectiveness of government interventions against COVID-19, there is still no study explaining the level of stringency of policies aimed at containing the pandemic, except for a study carried out by Islam et al. (2020) based on qualitative analysis. Based on 10 case studies from developed and developing countries, the authors concluded that improving the social security system and health care and governance are key determinants in combating the pandemic. Following Bal et al. (2020), who call for research on policymakers' and institutions' responses to this pandemic, we propose going further than the research work that has been carried out so far, by analyzing the determinants that led government authorities to implement more or less restrictive policies to fight the spread of the pandemic. Our paper bridges this gap by conducting a study based on the European example (EU countries, the United Kingdom, and Norway) and offers an unprecedented analysis using panel data from March 2020 to April 2021, including the first two waves in Europe. Our paper is structured as follows: First, we present the methodology used and the main results. Finally, as a discussion guide, we open a discussion about the implications for policymakers and international populations. 


\section{Materials and Methods}

In order to analyze the determinants of the measures taken to limit the spread of COVID-19, we used the COVID-19 stringency index of the countries as a dependent variable. The stringency index is a composite measure based on nine response indicators rescaled to a value from zero to $100(100=$ strictest $)$. If policies vary at the subnational level, the index shows the response level of the strictest sub-region. This index was computed by the Oxford COVID-19 Government Response Tracker (OxCGRT). The latter collects systematic information on policy measures that governments have taken to tackle COVID-19. It allowed us to assess the rigor level of government responses over time (Hale et al. 2020). The index records the strictness of 'lockdown style' policies that primarily restrict people's behavior. It is calculated using all ordinal containment and closure policy indicators and an indicator recording public information campaigns. The composite index is composed of different sub-indices that identify the main types of measure implemented: school closures (C1); workplace closures (C2); cancellation of public events (C3); restrictions on the size of gatherings (C4); public transport closure (C5); stay-at-home requirements (C6); internal movement restrictions (C7); international travel restrictions (C8); and public information campaigns (H1). The stringency index is a simple average of individual component indicators. It is calculated every day. ${ }^{1}$ For our analysis, we took the average of this index for the months covered by our study.

Various variables may explain the level of restriction in terms of public policies to combat COVID-19 (Table 1). ${ }^{2}$ Among them is the number of new deaths that occurred during a given month (NewDeath). We also took into account the evolution of the incidence for a given month (Incidence). The incidence rate corresponds to the number of positive tests per 100,000 inhabitants. A 14-day lag period was applied between the rigor index and the date on which the change in incidence was taken into account, according to a literature work on the subject (Lauer et al. 2020). These data were obtained from the Johns Hopkins Institute. $^{3}$

Table 1. Description of the variables.

\begin{tabular}{|c|c|c|}
\hline Variable & Description & Description \\
\hline Stringency Index & $\begin{array}{l}\text { Mean of the composite measure (based on nine response } \\
\text { indicators rescaled to a value from } 0 \text { to } 100 \\
(100=\text { strictest }) \text { ) for a given month }\end{array}$ & $\begin{array}{c}\text { Oxford COVID-19 Government Response } \\
\text { Tracker }\end{array}$ \\
\hline NewDeath & $\begin{array}{l}\text { Number of new deaths which occurred during a } \\
\text { given month }\end{array}$ & Johns Hopkins Institute \\
\hline Incidence & $\begin{array}{l}\text { Number of positive tests per } 100,000 \text { inhabitants during a } \\
\text { given month }\end{array}$ & Johns Hopkins Institute \\
\hline GDP/capita & GDP/capita in 2020 & Eurostat \\
\hline ICU beds & Number of ICU beds per country for a given month & $\begin{array}{l}\text { European Centre for Disease Prevention } \\
\text { and Control }\end{array}$ \\
\hline Elderly & $\begin{array}{l}\text { Number of people over } 70 \text { years old/total population } \\
\text { in } 2019\end{array}$ & World Bank \\
\hline Severe diseases & $\begin{array}{l}\text { Premature mortality from cardiovascular diseases, cancer, } \\
\text { diabetes and chronic respiratory diseases (between } 30 \text { and } \\
\qquad 70 \text { years) (\%) in } 2019\end{array}$ & World Bank \\
\hline
\end{tabular}

Table 2 presents the descriptive statistics of our database. 
Table 2. Descriptive statistics.

\begin{tabular}{lcccc}
\hline \multicolumn{1}{c}{ Variable } & Min & Max & Mean & Std. Dev. \\
\hline Stringency Index & 46.3 & 87.39 & 68.58 & 10.67 \\
New Death & 2 & 11,336 & 1208.50 & 2444.66 \\
Incidence & 1.8 & 425 & 59.25 & 90.54 \\
GDP/capita & $18,563.31$ & $94,277.97$ & $37,274.66$ & $15,239.80$ \\
ICU beds & 2.22 & 8 & 4.90 & 1.75 \\
Elderly & 8.56 & 16.24 & 12.58 & 1.97 \\
Severe diseases & 8.4 & 24.2 & 13.50 & 2.87 \\
\hline
\end{tabular}

In addition, we wanted to add a variable related to the country's level of wealth (GDP/capita), with the understanding that the more developed European countries were heavily affected at the beginning of the crisis and were, therefore, able to take action accordingly. At the same time, Walker et al. (2020) found a significant excess mortality rate in low-income countries, due to poor access to healthcare. As a result, in these countries, the stringency issue is critical, as hospitals are unlikely to manage a large influx of patients effectively. These data came from Eurostat. ${ }^{4}$

A determining variable that may explain the variation in the policies' stringency levels is related to the healthcare system's organization. The number of intensive care unit (ICU) beds was a significant factor when governments had to decide which measures were to be taken (Bal et al. 2020). However, as Bauer et al. (2020) explain, ICU provision is far from being the same across Europe. They showed that a low number of ICU was associated with a higher proportion of deaths due to COVID-19. Therefore, we added a variable relating to the number of ICU beds per country (ICU beds). These data were collected from the European Centre for Disease Prevention and Control. ${ }^{5}$

In the countries of our study, advisory committees composed of medical experts were established (WHO 2020). Political decisions were partly based on their advice (Stevens 2020). These committee members paid particular attention to epidemiological data. We added the number of people over 65 years old / total population (elderly) as a variable that possibly influenced the measures implemented, in keeping with the great number of articles that highlighted the elderly's excess mortality due to COVID-19 (see for example Yanez et al. 2020). In addition, following epidemiological studies, we also added the rate of premature mortality from cardiovascular diseases, cancer, diabetes, and chronic respiratory diseases (between 30 and 70 years). The literature has largely demonstrated that these diseases are important risk factors for mortality (see, for example, Bonow et al. 2020; Holman et al. 2020). These data were collected from the World Bank. ${ }^{6}$

To examine the association between the stringency index and the different variables mentioned above, we performed regression estimation using a panel data method under individual random-effects (1), individual fixed-effects (2), individual random effects, and time fixed-effects (3). The model was calculated with the data on new COVID-19 deaths monthly from March 2020 to April 2021 for European countries. ${ }^{7}$

\section{Results}

As we were using a panel data method, we also ran a Haussman specification test. The results are listed in Table 3 , where the $p$-value is 0.000 . The Hsiao specification test ended with a very good $p$-value of 0.000 , confirming an individual fixed-effects panel data model.

Table 3. Hausman specification test.

\begin{tabular}{cc}
\hline & Coef. \\
\hline Chi-square test value & 14.396 \\
$p$-value & 0.000 \\
\hline
\end{tabular}


We used the variance inflation factor (VIF) to test for multicollinearity. This is not an issue in our model; the maximum is for capacities with a VIF of 5.29, that is, the standard error for the coefficient of that predictor variable is 2.22 times larger than if that predictor variable had zero correlation with the other predictor variables.

First, we observed a positive and still significant effect of the incidence rate on the stringency level (Table 4). From this point of view, we can say that the scale of the COVID-19 crisis indeed drove the decision-making process in terms of COVID-19 controls. Regarding the number of new deaths, the effect was positive and very significant.

Table 4. Panel model: Results.

\begin{tabular}{|c|c|c|c|c|c|c|}
\hline \multirow[b]{3}{*}{ Variable } & \multicolumn{2}{|c|}{ (1) } & \multicolumn{2}{|c|}{ (2) } & \multicolumn{2}{|c|}{ (3) } \\
\hline & \multicolumn{2}{|c|}{ GLS Random Effects } & \multicolumn{2}{|c|}{ Individual Fixed } & \multicolumn{2}{|c|}{ Individual Random and Time Fixed } \\
\hline & Value & $\operatorname{Pr}>|t|$ & Value & $\operatorname{Pr}>|\mathrm{t}|$ & Value & $\operatorname{Pr}>|\mathrm{t}|$ \\
\hline NewDeath & 0.009 & $<0.0001$ & 0.006 & 0.001 & 0.005 & 0.001 \\
\hline Incidence & 0.002 & $<0.0001$ & 0.001 & 0.033 & 0.001 & 0.005 \\
\hline GDP/capita & 0.003 & 0.008 & 0.003 & 0.02 & 0.014 & 0.02 \\
\hline ICU beds & 2.516 & 0.032 & 1.84 & 0.039 & 1.36 & 0.03 \\
\hline Elderly & 0.389 & 0.02 & 0.066 & 0.025 & 0.241 & 0.027 \\
\hline Severe Diseases & -4.318 & $<0.0001$ & -1.909 & 0.033 & -1.2 & 0.002 \\
\hline Ajusted $\mathrm{R}^{2}$ & 0.619 & & 0.631 & & 0.607 & \\
\hline F-statistic & 15.49 & $<0.0001$ & 19.11 & $<0.0001$ & 9.65 & 0.002 \\
\hline Number of observations & 364 & & 364 & & 364 & \\
\hline
\end{tabular}

For the wealth variable sign (GDP/capita), a positive and significant effect was observed, since the rich European countries were primarily affected at the beginning of the crisis and remained highly hit by COVID-19 across the period.

We also observed a highly positive and significant effect of ICU/beds on the stringency level. Given the pressure on the health system at the height of the crisis, national authorities attached a lot of importance to patient capacity. The management of patients suffering from COVID-19 during the spring 2020 epidemic wave heavily relied on intensive care capacity and surveillance systems. Given that the average length of stay observed was 12 days, the pressure was at its peak in April 2020. At that time, in several EU countries, saturation was observed in these services.

At the beginning of the crisis, the share of older people in the total population was not a variable that influenced the decision to implement more or less restrictive measures. In March, epidemiological data were still insufficient to highlight the impact of age on COVID-19 mortality. Subsequently, given the number of deaths in residential care homes for dependent older people, national governments took this variable seriously into account as part of their decision-making process. This situation can explain why the coefficient for the elderly is positive and significant.

Concerning epidemiological data, there is a significant negative effect on premature mortality from cardiovascular diseases, cancer, diabetes, and chronic respiratory diseases. Although this may seem counterintuitive, it is not surprising. This suggests that factors other than health evidence have driven national policymakers' choices.

\section{Discussion}

Since the worsening of the coronavirus pandemic, many countries, particularly in Europe, have taken a wide variety of measures at different levels. This non-universal approach can be explained by the factors previously highlighted in this article. The contexts are very different in terms of policy, care organization, and outbreaks. Health systems in European countries are very diverse and result from history, political traditions, and socioeconomic specificities. As a result, their organization is very diverse in terms of the financial and human resources allocated to them and how they are financed. Since the 1980s, a double 
movement has affected these health systems: privatization and new public management. Privatization involves the financing of the private sector with public funds, the financing of the public sector with private resources, public-private partnerships, contracts between public authorities (regions, public insurance schemes) and private care providers, contracts between public hospitals and private clinics, and the private practice of doctors in public hospitals (Albreht 2009). Such intertwining is taken to extremes in some southern countries, such as Spain (Gallo and Gené-Badia 2013). So much so that, as Navarro (2020) explains, this privatization has had a negative impact on COVID-19 mortality. Countries such as Spain and Italy, which have experienced drastic decreases in the resources allocated to the health system over the last few decades, have seen important consequences for their health management during the crisis (Kapitsinis 2020). Three decades ago, a new form of management introduced greater autonomy, accompanied by the constraints of financial balance, market, and competition mechanisms and new modes of governance, and was supposed to improve efficiency, but is now showing its limits in a pandemic context (Holzer and Newbold 2020; Mauro and Giancotti 2021). All of this may explain why countries have been able to employ restrictive measures, sometimes very severe, precisely to mitigate the effects of the neoliberal reform of the health system (Navarro 2020). Since some countries knew that their health care systems would not manage, strict containment measures were put in place to avoid any overwhelming of health care services.

Our study shows that some factors played an important role in defining scale of restrictions and the level of measures taken. Among them, equipment availability is a crucial issue. There are three times as many intensive care beds in Germany as in France or other countries. This was also emphasized by Islam et al. (2020) in their study of ten countries around the world. The issue of the supply (quantity and level) of health care plays a decisive role. In addition, from a medical point of view, countries were faced with different volumes of patients, in terms of patients admitted to intensive care units. As a result, the choices made between countries may have differed.

Our study shows that the level of the so-called 'at-risk' population with severe diseases did not influence the policy rigor level. Indeed, as Forman et al. (2020) explained, the government responses in terms of intensity and speed were sometimes disconnected from the epidemiological evidence. On the other hand, we showed that more restrictive measures were taken in countries with a higher share of older people. In this case, containment policies aimed to reduce the general population's interactions with the elderly.

A second important driver that has influenced the severity of the measures is the impact of COVID-19 on economic activities. Unfortunately, to date, we do not have data to measure this. While measures to confine the entire population appear to be the most effective in reducing mortality, they also have negative consequences for the economy (Elgin et al. 2020) and finance (Ashraf 2020). Consequently, as Anderson et al. (2020) point out, these measures have raised the question of trade-offs between the medical aspect (reducing transmission and avoiding the exposure of at-risk people, to prevent as many deaths as possible) and the economic aspect (limiting the effects of health measures, such as containment). Moreover, those measures were more or less well-received depending on the country, and this may have affected trust, the behaviors toward the government, and the population's well-being (Sabat et al. 2020; Sibley et al. 2020).

At the same time, although the economic impact of the crisis can be thought of as a variable that influenced public stringency policies, the economic impact of the COVID-19 crisis can also be regarded as a consequence of management strategies regarding the crisis. Finally, as Kochańczyk and Lipniacki (2021) point out, as long as eradicating the virus remains the goal, the trade-off between the number of deaths and the economic losses is illusory. Consequently, the decision-making process regarding the stringency level of the measures implemented to combat the spread of COVID-19 became very complex, because of the number of parameters that had to be taken into account. 


\section{Conclusions and Policy Recommendations}

The aim of our paper was to analyze what determined the level of stringency implemented by European countries. Our results show positive and significant effects related to mortality and incidence of COVID-19. We also show that more developed countries often implemented more restrictive measures. Finally, while we showed that the share of older people had a positive effect on the stringency level, we observed a strong negative and significant effect of the share of the population with premature mortality from cardiovascular diseases, cancer, diabetes, and chronic respiratory diseases on the stringency index. There are methodological and other limitations to our research. Given the method used, we did not carry out longitudinal analyses to analyze the extent to which the determinants' signs and levels of significance may or may not have changed over time. Future research could further investigate these aspects of temporality/evolution.

The COVID-19 crisis revealed a severe lack of coordination between EU states in the choice of restrictive measures. While some countries were considering lifting their measures, others continued to apply them. However, given the overall lack of border closures in Europe, some countries that had relaxed some of the measures taken experienced setbacks in incidence rates and deaths, partly related to cross-border mobility. Therefore, we agree with what Forman et al. (2020) explained in their article; that countries need to confer more often and avoid making decisions in isolation. At the same time, the difficulty lies in the fact that each country experienced very different levels of intensity and speed of COVID-19 propagation (Bourdin et al. 2020), and the implementation of a one-size-fits-all European policy in terms of restrictive measures could have had unexpected effects. Consequently, this is all about implementing place-based policies, while placing the states' coordination issues at the heart of the matter. As McKee (2020) points out, this coordination is crucial, particularly in border areas.

Finally, although the COVID-19 crisis has shown the resilience of our public health systems (De Ceukelaire and Bodini 2020), it has also highlighted that the latter were insufficiently prepared for such intense pressure (Forman et al. 2020). Thus, many questions remain unanswered about national and local governments' capacity to cushion shocks. Depending on the state of preparedness and diffusion, which will depend on treatment, the number of households, and social or individual practices, it is clear that differences in mortality will persist and that countries will emerge from this crisis at different levels. Everyone will not necessarily be tested and vaccinated, so it will be challenging to determine whether the risk is higher in different countries. Regardless, it is clear that this will happen at a gradual and irregular pace.

Author Contributions: Conceptualization, S.B., S.B.M. and J.S.; methodology, S.B., S.B.M. and J.S.; software, S.B. and J.S.; validation, S.B., S.B.M. and J.S.; formal analysis, S.B.; investigation, S.B. and J.S.; resources, S.B. and J.S.; data curation, S.B. and J.S.; writing-original draft preparation, S.B., S.B.M. and J.S.; writing-review and editing, S.B.; supervision, S.B.; funding acquisition, S.B. All authors have read and agreed to the published version of the manuscript.

Funding: This research received no external funding.

Institutional Review Board Statement: Not applicable.

Informed Consent Statement: Not applicable.

Acknowledgments: This work was supported in part by the French Ministry for Europe and Foreign Affairs via the project "REPAIR COVID-19-Africa" coordinated by the Pasteur International Network association.

Conflicts of Interest: The authors declare no conflict of interest. 


\section{Notes}

1 To learn more about the methodology used to calculate the stringency index, see: https:/ / github.com/OxCGRT/covid-policytracker/blob/master/documentation/index_methodology.md (accessed on 5 January 2022).

2 Our database is the result of the compilation of different databases from different organisations. We were able to compile data monthly from those concerning epidemiology. On the other hand, economic data (GDP/capita) and demographic and health data (elderly and severe diseases) could only be collected on a yearly basis. This is a limitation of our database, but unfortunately the producing organizations do not publish such data on a monthly basis.

3 Coronavirus 2019-nCoV, CSSE. Coronavirus 2019-nCoV Global Cases and Deaths by the Center for Systems Science and Engineering (CSSE) at Johns Hopkins University (JHU).

4 See Eurostat: https:/ / ec.europa.eu/eurostat/web/products-datasets/-_sdg_08_10 (accessed on 5 January 2000).

5 See ECDPC: https://www.ecdc.europa.eu/en/covid-19/data (accessed on 5 January 2000).

6 See World Bank: https:// data.worldbank.org/indicator/SP.POP.65UP.TO.ZS (accessed on 5 January 2000) and https://data. worldbank.org/indicator/SH.DYN.NCOM.ZS (accessed on 5 January 2000).

7 All the countries of the European Union (except Malta, where no data were available regarding our dependant variable), Norway and the United Kingdom.

\section{References}

Albreht, Tit. 2009. Privatization processes in health care in Europe-A move in the right direction, a 'trendy'option, or a step back? The European Journal of Public Health 19: 448-50. [CrossRef] [PubMed]

Alfano, Vincenzo, and Salvatore Ercolano. 2020. The efficacy of lockdown against COVID-19: A cross-country panel analysis. Applied Health Economics and Health Policy 18: 509-17. [CrossRef]

Anderson, Roy M., Hans Heesterbeek, Don Klinkenberg, and T. Déirdre Hollingsworth. 2020. How will country-based mitigation measures influence the course of the COVID-19 epidemic? The Lancet 395: 931-34. [CrossRef]

Ashraf, Badar Nadeem. 2020. Economic impact of government interventions during the COVID-19 pandemic: International evidence from financial markets. Journal of Behavioral and Experimental Finance 27: 100371. [CrossRef]

Bal, Roland, Bert de Graaff, Hester van de Bovenkamp, and Iris Wallenburg. 2020. Practicing Corona-Towards a research agenda of health policies. Health Policy 124: 671-73. [CrossRef] [PubMed]

Bauer, Jan, Dörthe Brüggmann, Doris Klingelhöfer, Werner Maier, Lars Schwettmann, Daniel J. Weiss, and David A. Groneberg. 2020. Access to intensive care in 14 European countries: A spatial analysis of intensive care need and capacity in the light of COVID-19. Intensive Care Medicine 46: 2026-34. [CrossRef]

Bonow, Robert O., Gregg C. Fonarow, Patrick T. O'Gara, and Clyde W. Yancy. 2020. Association of coronavirus disease 2019 (COVID-19) with myocardial injury and mortality. JAMA Cardiology 5: 751-53. [CrossRef]

Bourdin, Sebastien, Ludovic Jeanne, Fabien Nadou, and Gabriel Noiret. 2021. Does lockdown work? A spatial analysis of the spread and concentration of COVID-19 in Italy. Regional Studies 55: 1182-93. [CrossRef]

Bourdin, Sébastien, Nicolas Rossignol, Mounir Amdaoud, Giuseppe Arcuri, Damiana Costanzo, Mihail Eva, and Corneliu Iatu. 2020. Geography of COVID-19 Outbreak and First Policy Answers in European Regions and Cities. ESPON Report. Luxembourg: ESPON Luxembourg.

Caselli, Mauro, Andrea Fracasso, and Sergio Scicchitano. 2020. From the Lockdown to the New Normal: An Analysis of the Limitations to Individual Mobility in Italy Following the COVID-19 Crisis (No. 683). GLO Discussion Paper. Hamburg: ZBW-Leibniz Information Centre for Economics.

Cowling, Benjamin J., Sheikh Taslim Ali, Tiffany W. Y. Ng, Tim K. Tsang, Julian C. M. Li, Min Whui Fong, Qiuyan Liao, Mike Y. W. Kwan, So Lun Lee, and Susan S. Chiu. 2020. Impact assessment of non-pharmaceutical interventions against coronavirus disease 2019 and influenza in Hong Kong: An observational study. The Lancet Public Health 5: e279-88. [CrossRef]

Davies, Nicholas G., Adam J. Kucharski, Rosalind M. Eggo, Amy Gimma, W. John Edmunds, Thibaut Jombart, and Kathleen O’Reilly. 2020. The effect of non-pharmaceutical interventions on COVID-19 cases, deaths and demand for hospital services in the UK: A modelling study. Lancet 5: E375-85. [CrossRef]

De Ceukelaire, Wim, and Chiara Bodini. 2020. We need strong public health care to contain the global corona pandemic. International Journal of Health Service 50: 276-77. [CrossRef]

Elgin, Ceyhun, Gokce Basbug, and Abdullah Yalaman. 2020. Economic policy responses to a pandemic: Developing the COVID-19 economic stimulus index. COVID Economics 1: 40-53.

Figueiredo, Alexandre M., A. Daponte Codina, D. C. M. M. Figueiredo, M. Saez, and A. Cabrera León. 2020. Impact of lockdown on COVID-19 incidence and mortality in China: An interrupted time series study. Bull World Health Organ 6. [CrossRef]

Flaxman, Seth, Swapnil Mishra, Axel Gandy, H. Juliette T. Unwin, Thomas A. Mellan, Helen Coupland, Charles Whittaker, Harrison Zhu, Tresnia Berah, and Jeffrey W. Eaton. 2020. Estimating the effects of non-pharmaceutical interventions on COVID-19 in Europe. Nature 584: 257-61. [CrossRef] [PubMed]

Forman, Rebecca, Rifat Atun, Martin McKee, and Elias Mossialos. 2020. 12 Lessons learned from the management of the coronavirus pandemic. Health Policy 124: 577-80. [CrossRef] [PubMed] 
Gallo, Pedro, and Joan Gené-Badia. 2013. Cuts drive health system reforms in Spain. Health Policy 113: 1-7. [CrossRef]

Hale, Thomas, S. Webster, A. Petherick, T. Phillips, and B. Kira. 2020. Oxford COVID-19 Government Response Tracker (OxCGRT). Oxford: Oxford University.

Holman, Naomi, Peter Knighton, Partha Kar, Jackie O'Keefe, Matt Curley, Andy Weaver, Emma Barron, Chirag Bakhai, Kamlesh Khunti, Nicholas J Wareham, and et al. 2020. Risk factors for COVID-19-related mortality in people with type 1 and type 2 diabetes in England: A population-based cohort study. The Lancet Diabetes E Endocrinology 8: 823-33.

Holzer, Marc, and Stephanie P. Newbold. 2020. A call for action: Public administration, public policy, and public health responses to the COVID-19 pandemic. The American Review of Public Administration 50: 450-54. [CrossRef]

IMF. 2020. IMF Policy Tracker 2020. Available online: https://www.imf.org/en/Topics/imf-and-covid19/Policy-Responses-toCOVID-19 (accessed on 5 January 2022).

Islam, S. Nazrul, Hoi Wai Jackie Cheng, Kristinn Helgason, Nicole Hunt, Hiroshi Kawamura, and Marcelo LaFleur. 2020. Variations in COVID Strategies: Determinants and Lessons. No. 172. New York: United Nations, Department of Economic and Social Affairs.

Jorge, Daniel C. P., Moreno S. Rodrigues, Mateus S. Silva, Luciana L. Cardim, Nívea B. da Silva, Ismael H. Silveira, Vivian A. F. Silva, Felipe A. C. Pereira, Arthur R. de Azevedo, Alan A. S. Amad, and et al. 2020. Assessing the nationwide impact of COVID-19 mitigation policies on the transmission rate of SARS-CoV-2 in Brazil. Epidemics 35: 100465. [CrossRef]

Kamerlin, Shina C. L., and Peter M. Kasson. 2020. Managing COVID-19 spread with voluntary public-health measures: Sweden as a case study for pandemic control. Clinical Infectious Diseases 71: 3174-81. [CrossRef]

Kapitsinis, Nikos. 2020. The underlying factors of the COVID-19 spatially uneven spread. Initial evidence from regions in nine EU countries. Regional Science Policy E Practice 12: 1027-45.

Kochańczyk, Marek, and Tomasz Lipniacki. 2021. Pareto-based evaluation of national responses to COVID-19 pandemic shows that saving lives and protecting economy are non-trade-off objectives. Scientific Reports 11: 2425. [CrossRef]

Lau, Hien, Veria Khosrawipour, Piotr Kocbach, Agata Mikolajczyk, Justyna Schubert, Jacek Bania, and Tanja Khosrawipour. 2020. The positive impact of lockdown in Wuhan on containing the COVID-19 outbreak in China. Journal of Travel Medicine 27: taaa037. [CrossRef] [PubMed]

Lauer, Stephen A., Kyra H. Grantz, Qifang Bi, Forrest K. Jones, Qulu Zheng, Hannah R. Meredith, Andrew S. Azman, Nicholas G. Reich, and Justin Lessler. 2020. The incubation period of coronavirus disease 2019 (COVID-19) from publicly reported confirmed cases: Estimation and application. Annals of Internal Medicine 172: 577-82. [CrossRef] [PubMed]

Maier, Benjamin F., and Dirk Brockmann. 2020. Effective containment explains subexponential growth in recent confirmed COVID-19 cases in China. Science 368: 742-46. [CrossRef] [PubMed]

Mauro, Marianna, and Monica Giancotti. 2021. Italian responses to the COVID-19 emergency: Overthrowing 30 years of health reforms? Health Policy 125: 548-52. [CrossRef]

McKee, Martin. 2020. A European roadmap out of the COVID-19 pandemic. BMJ 369: m1556. [CrossRef] [PubMed]

Navarro, Vicente. 2020. The consequences of neoliberalism in the current pandemic. International Journal of Health Services 50: 271-75. [CrossRef]

Sabat, Iryna, Sebastian Neuman-Böhme, Nirosha Elsem Varghese, Pedro Pita Barros, Werner Brouwer, Job van Exel, Jonas Schreyögg, and Tom Stargardt. 2020. United but divided: Policy responses and people's perceptions in the EU during the COVID-19 outbreak. Health Policy 124: 909-18. [CrossRef]

Sardar, Tridip, Sk Shahid Nadim, Sourav Rana, and Joydev Chattopadhyay. 2020. Assessment of 21 days lockdown effect in some states and overall India: A predictive mathematical study on COVID-19 outbreak. Chaos, Solitons E Fractals 139: 110078.

Sibley, Chris G., Lara M. Greaves, Nicole Satherley, Marc S. Wilson, Nickola C. Overall, Carol H. J. Lee, Petar Milojev, Danny Osborne, Taciano L. Milfont, Carla A. Houkamau, and et al. 2020. Effects of the COVID-19 pandemic and nationwide lockdown on trust, attitudes toward government, and well-being. American Psychologist 75: 618. [CrossRef] [PubMed]

Stevens, Alex. 2020. Governments cannot just 'follow the science' on COVID-19. Nature Human Behaviour 4: 560-60. [CrossRef] [PubMed]

Walker, Patrick G. T., Charles Whittaker, Oliver J. Watson, Marc Baguelin, Peter Winskill, Arran Hamlet, and Bimandra A. Djafaara. 2020. The impact of COVID-19 and strategies for mitigation and suppression in low-and middle-income countries. Science 369: 413-22. [CrossRef] [PubMed]

Weick, Karl E., and Kathleen M. Sutcliffe. 2011. Managing the Unexpected: Resilient Performance in an Age of Uncertainty. Hoboken: John Wiley \& Sons, vol. 8.

World Health Organization. 2020. Coronavirus Disease (COVID-19): Situation Report. Geneva: WHO, p. 185.

Yanez, N. David, Noel S. Weiss, Jacques-André Romand, and Miriam M. Treggiari. 2020. COVID-19 mortality risk for older men and women. BMC Public Health 20: 1742. [CrossRef] [PubMed]

Zhu, Dongshan, Shiva Raj Mishra, Xikun Han, and Karla Santo. 2020. Social distancing in Latin America during the COVID-19 pandemic: An analysis using the Stringency Index and Google Community Mobility Reports. Journal of Travel Medicine 27: taaa125. [CrossRef] 